\title{
The role of SIRT1 in tumorigenesis
}

\author{
Kai Li, Ph.D. and Jianyuan Luo, Ph.D.* \\ Department of Medical \& Research Technology, Department of Pathology, School of Medicine, \\ University of Maryland, AHB 405A, 100 Penn Street, Baltimore, MD 21201
}

\begin{abstract}
NAD-dependent Class III histone deacetylase SIRT1 is a multiple functional protein and has been demonstrated critically involved in stress response, cellular metabolism and aging through deacetylating variety of substrates including p53, forkhead transcription factors, PGC-1a, NF- $\kappa \mathrm{B}$, Ku70 and histones. Increasing evidences indicate that SIRT1 plays a complex role in tumorigenesis with functions in both tumor promoting and tumor suppressing. This review provides an overview of current knowledge of SIRT1 and its controversies regarding the functions of SIRT1 in tumorigenesis.
\end{abstract}

\section{Keywords}

SIRT1; deacetylase; cancer

\section{Introduction}

SIRT1 is the human homolog of yeast Sir2 (silent information regulator 2) and belongs to a novel family of histone deacetylase.Sir2 is involved in gene silencing, telomere position effects, and cellular aging ${ }^{1}$. The NAD-dependent deacetylase activity is essential for its functions, and connects its biological role with cellular metabolism. ${ }^{1-3}$ An extra copy of Sir2 gene can increase yeast life span, while deletion of Sir2 shorten life span. ${ }^{4}$ Sir2 homologs have been found in all organisms from bacteria to human, and they also involve the regulation of life span of these organisms. Increased dosage of sir- 2.1 gene, the homologous to yeast Sir2, extends life spanin $C$. elegans. ${ }^{5}$ Increasing the copy number of dSIR2, the homolog of yeast Sir2, also extends life span in Drosophila. ${ }^{6}$ Activating SIRT1 by resveratrol improves health and survival of mice on a high-calorie diet. ${ }^{7}$ Besides the important role in life span extension, SIRT1 also plays a complex role in tumorigenesis with dual functions in tumor promoter and tumor suppressor.

The process of tumorigenesis is the transformation of normal cells to tumor cells. This process is companied with progressive changes on cells and leads to uncontrolled cell growth and division. Tumor promoter genes function on promoting cell transformation while tumor suppressor genes function to inhibit tumorigenesis. ${ }^{8}$ Both tumor promoters and tumor suppressors are important in tumor development. The controversial role of SIRT1 in tumorigenesis with opposite functions underscores the complex regulation of SIRT1 in the process.

*Correspondent author: Jianyuan Luo, Ph.D. JLuo@ som.umaryland.edu. 


\section{SIRT1 as a tumor promoter}

SIRT1 was originally considered as a tumor promoter due to its first identified target was tumor suppressor $\mathrm{p} 53$. SIRT1 physically interacts with and deacetylates $\mathrm{p} 53$ and represses p53 dependent apoptosis in response to DNA damage, while a dominant negative SIRT1 mutant increases cell sensitivity to stress. SIRT1 deacetylation of p53 antagonizes PML/ p53-induced cellular senescence. ${ }^{9-11}$ Moreover, cells from SIRT1 knockout mice exhibit p53 hyperacetylation after DNA damage and increased ionizing radiation-induced thymocyte apoptosis. ${ }^{12}$ SIRT1 also regulates FOXO3a, a member of the FOXO family of forkhead transcription factors, which regulates apoptosis. SIRT1 interacts with and deacetylates FOXO3a. Deacetylation of FOXO3a represses its transcriptional activation activity and inhibits its ability to induce apoptosis. ${ }^{13-14}$ Transcription factor E2F1, which stimulates the transcription of several pro-apoptotic genes, ${ }^{15}$ is another protein regulated by SIRT1. Deacetylation of E2F1 by SIRT1 inhibits its activity as a transcription activator. Furthermore, E2F1 can increase SIRT1 transcription level, forming a negative-feedback loop. ${ }^{16}$ SIRT1 also regulates another well-known tumor suppressor Retinoblastoma (Rb). SIRT1 deacetylates $\mathrm{Rb}$ and inhibits cell cycle arrest. ${ }^{17}$

Strong evidence that SIRT1 function as tumor promoter comes from the findings that SIRT1 expression is significantly increased in several murine and human cancer cells. SIRT1 is consistently overexpressed in acute myeloid leukemia, ${ }^{18}$ mouse and human prostate cancer cells, ${ }^{19}$ colon carcinoma cells. ${ }^{20}$ many kinds of non-melanoma skin cancers, ${ }^{21}$ cutaneous human squamous celland basal cell carcinoma. ${ }^{22}$ Down-regulation of SIRT1 induces growth arrest and apoptosis in human epithelial cancer cells ${ }^{23}$ and Burkitt lymphoma cells. ${ }^{24}$ Inhibition of SIRT1 activity by Sirtinol (a SIRT1 inhibitor) induces senescence-like cell growth arrest with attenuated Ras-MAPK signaling in human cancer cells. ${ }^{25} \mathrm{DBC} 1$ (deleted in breast cancer 1) acts as a native inhibitor of SIRT1 in human cells. Repression of SIRT1 by $\mathrm{DBC} 1$ leads to increased level of $\mathrm{p} 53$ acetylation and upregulation of p53 function. ${ }^{26-27}$ The above findings indicate that gain of function by overexpression of SIRT1 inhibits cell growth arrest and apoptosis and loss of SIRT1 function in above cancer cells induces apoptosis. Therefore, SIRT1 acts as a tumor promoter in these cancer cells. In these cases, SIRT1 inhibitors are the idea targets for developing potential anti-cancer drugs. Indeed, Lain and colleagues carried out a cell-based screen and discovered that SIRT1 is a target of a soluble small molecule, tenovin-6, in mammalian cells. Inhibition of SIRT1 by tenovin-6 causes p53 hyperacetylation, increases p53-depedent transcriptional activity and delays tumor growth in vivo. ${ }^{28}$ Significantly, tenovins are active on mammalian cells at one-digit micromolar concentrations making them an idea candidates for potential therapeutic targets. ${ }^{28}$

\section{SIRT1 as a tumor suppressor}

Recent studies indicate that SIRT1 may serve as a tumor suppressor in some cases as well. SIRT1 suppresses intestinal tumorigenesis and colon cancer growth by deacetylating $\beta$ catenin and suppresses its ability to activate transcription and drive cell proliferation. SIRT1 also promotes cytoplasmic localization of the otherwise nuclear-localized oncogenic form of $\beta$-catenin in a $\beta$-catenin-driven mouse model of colon cancer and significantly reduces tumor formation and proliferation. ${ }^{29}$ BRCA-1 plays an important role in DNA repair, cell cycle, transcription regulation and apoptosis. ${ }^{30}$ SIRT1 expression level is much lower in BRCA-1mutant cancer cells than BRCA-1 wild-type cancer cells. BRCA1 activates SIRT1 expression, and restoration of SIRT1 in BRCA1 mutant cancer cells suppresses tumor formation. Survivin is a small inhibitor of apoptosis protein differentially overexpressed in variety cancers and a validated target for cancer drug discovery. ${ }^{31}$ BRCA1 is found at the SIRT1 promoter and increases SIRT1 expression which in turn inhibits Survivin expression 
by deacetylation of histone $\mathrm{H} 3$ of the promoter. Importantly, resveratrol, a SIRT1 activator, can inhibit Survivin expression, serves a potential targeted therapy for BRCA1-associated breast cancer. ${ }^{32}$ SIRT1 also interacts with the RelA/p65 subunit of NF- $\kappa \mathrm{B}$, and inhibits transcriptional activity by deacetylation. Cells with deacetylated NF- $\kappa \mathrm{B}$ are more sensitive to TNF a-induced apoptosis. ${ }^{33}$

SIRT1 expression level was also found reduced in many cancer cells compared to normal tissue, including glioblastoma, bladder carcinoma, prostate carcinoma, and various forms of ovarian cancers. ${ }^{3}$ Increasing evidences indicate that SIRT1 also plays an important role in DNA repair pathways. SIRT1 knockout mice showed increasing genomic instability due to impaired DNA repair. ${ }^{34}$ Upon exposure to ionizing radiation, SIRT1 deacetylates repair protein Ku70 and enhances DNA repair capacity. ${ }^{35}$ SIRT1 deacetylates WRN protein to regulate its enzymatic activities and cellular localization to facilitate DNA repair in cells. ${ }^{36}$ SIRT1 also plays a positive role in repairing double-strand DNA breaks through deacetylating NBS1 and maintaining NBS1 in a hypoacetylated state. ${ }^{37}$ In response to oxidative stress and ionizing irradiation, SIRT1 dissociates from repetitive DNA foci and relocalizes to DNA breaks to promote DNA repair. ${ }^{38}$ SIRT1 also regulates UV-induced DNA damage repair by deacetylating XPA of NER pathway to facilitate repair of UVinduced DNA damage lesion. ${ }^{39}$

SIRT1 knockout mice have allowed further understanding of the roles of SIRT1 in tumorigenesis. SIRT1-deficient mice were employed to study SIRT1 functions by several independent groups. ${ }^{34,40-41}$ The contradict functions of SIRT1 in tumorigenesis also shown in mouse models. As SIRT1-null mice are mostly embryonic lethal, the role of SIRT1 in tumorigenesis could not be directly assessed from them. ${ }^{34,40-41}$ However, several SIRT1 tissue specific knockout strains have been established and those mice did not display tumorigenesis phenotype at all. ${ }^{42-47}$ The early models showed that the SIRT1 knockout mice have hyperacetylated $\mathrm{p} 53$ and exhibit increased apoptosis, at least in thymocytes ${ }^{41}$ and spermatogonia. ${ }^{40}$ The more recently published SIRT1 knockout mouse model, however, showed severe genomic impairment including extensive aneuploidy and diverse

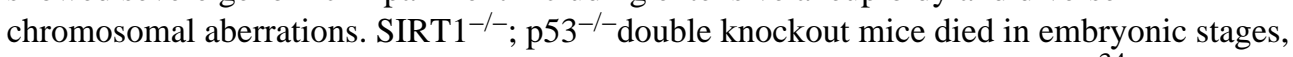
indicating that SIRT1 deficiency likely causes other essential pathway defects. ${ }^{34}$

Intriguingly, double heterozygotic SIRT1+/-; p53+/- mice survived but exhibited a remarkably high incidence (76\%) of tumors, while only two of 21 SIRT1+/- mice and 3 of $23 \mathrm{p} 53+/-$ mice developed tumors. Further analysis of tumor tissues in double heterozygotic mice showed $73 \%$ of the tumors had lost p53 expression and $44 \%$ tumors had little or no SIRT $1 .{ }^{34}$ These findings suggest that genomic integrity and stability require cooperation of p53 and SIRT1. As cancer has been considered as a set of diseases driven by epigenetic changes and genetic modifications in oncogenes and/or tumor suppressors, it seems likely that elaborate and complex signal networks protect genome integrity in cells. With insufficiency of SIRT1 or p53 alone, compensatory signal pathways may be activated or enhanced to inhibit tumorigenesis. With loss of both SIRT1 and p53, cells appear to lose control of genomic integrity, and these cells could be at greater risk for development of tumors.

\section{Conclusion mark}

The apparent opposite role of SIRT1 seems contradictory at first but the multiple functions of SIRT1 made this possible. SIRT1 can negatively regulate multiple pathways including both tumor suppressors (p53, FOXO) and oncogenic proteins (Survivin, $\beta$-catenin, NF- kB). In each specific circumstance, which pathway has been dominantly regulated decided the outcome of tumor suppressing or tumor promoting. Which face that SIRT1 shows up in tumorigenesis may well depends on the temporal and special distribution of different SIRT1 
upstream regulators anddownstream targets. Obviously, more intense research is necessary in order to understand the complex role of SIRT1 in tumorigenesis.

\section{References}

1. Guarente L. Sir2 links chromatin silencing, metabolism, and aging. Genes Dev. 2000; 14(9):10211026. [PubMed: 10809662]

2. Imai S, Johnson FB, Marciniak RA, McVey M, Park PU, Guarente L. Sir2: an NAD-dependent histone deacetylase that connects chromatin silencing, metabolism, and aging. Cold Spring Harb Symp Quant Biol. 2000; 65:297-302. [PubMed: 12760043]

3. Lin SJ, Defossez PA, Guarente L. Requirement of NAD and SIR2 for life-span extension by calorie restriction in Saccharomyces cerevisiae. Science. 2000; 289(5487):2126-2128. [PubMed: 11000115]

4. Kaeberlein M, McVey M, Guarente L. The SIR2/3/4 complex and SIR2 alone promote longevity in Saccharomyces cerevisiae by two different mechanisms. Genes Dev. 1999; 13(19):2570-2580. [PubMed: 10521401]

5. Tissenbaum HA, Guarente L. Increased dosage of a sir-2 gene extends lifespan in Caenorhabditis elegans. Nature. 2001; 410(6825):227-230. [PubMed: 11242085]

6. Rogina B, Helfand SL. Sir2 mediates longevity in the fly through a pathway related to calorie restriction. Proc Natl Acad Sci USA. 2004; 101(45):15998-16003. [PubMed: 15520384]

7. Baur JA, et al. Resveratrol improves health and survival of mice on a high-calorie diet. Nature. 2006; 444(7117):337-342. [PubMed: 17086191]

8. Knudson AG. Two genetic hits (more or less) to cancer. Nat. Rev.Cancer. 2001; 1(2):157-162. [PubMed: 11905807]

9. Luo J, Nikolaev AY, Imai S, et al. Negative control of p53 by Sir2alpha promotes cell survival under stress. Cell. 2001; 107(2):137-148. [PubMed: 11672522]

10. Vaziri H, Dessain SK, Ng Eaton E, et al. hSIR2(SIRT1) functions as an NAD-dependent p53 deacetylase. Cell. 2001; 107(2):149-159. [PubMed: 11672523]

11. Langley E, Pearson M, Faretta M, et al. Human SIR2 deacetylates p53 and antagonizes PML/p53induced cellular senescence. EMBO J. 2002; 21(10):2383-2396. [PubMed: 12006491]

12. Cheng HL, Mostoslavsky R, Saito S, et al. Developmental defects and p53 hyperacetylation in Sir2 homolog (SIRT1)-deficient mice. Proc Natl Acad Sci USA. 2003; 100(19):10794-10799. [PubMed: 12960381]

13. Motta MC, Divecha N, Lemieux M, et al. Mammalian SIRT1 represses forkhead transcription factors. Cell. 2004; 116(4):551-563. [PubMed: 14980222]

14. Brunet A, Sweeney LB, Sturgill JF, et al. Stress-dependent regulation of FOXO transcription factors by the SIRT1 deacetylase. Science. 2004; 303(5666):2011-2015. [PubMed: 14976264]

15. Nahle Z, Polakoff J, Davuluri RV, et al. Direct coupling of the cell cycle and cell death machinery by E2F. Nat Cell Biol. 2002; 4(11):859-864. [PubMed: 12389032]

16. Wang C, Chen L, Hou X, et al. Interactions between E2F1 and SirT1 regulate apoptotic response to DNA damage. Nat Cell Biol. 2006; 8(9):1025-1031. [PubMed: 16892051]

17. Wong S, Weber JD. Deacetylation of the retinoblastoma tumour suppressor protein by SIRT1. Biochem J. 2007; 407(3):451-460. [PubMed: 17620057]

18. Bradbury CA, Khanim FL, Hayden R, et al. Histone deacetylases in acute myeloid leukaemia show a distinctive pattern of expression that changes selectively in response to deacetylase inhibitors. Leukemia. 2005; 19(10):1751-1759. [PubMed: 16121216]

19. Huffman DM, Grizzle WE, Bamman MM, et al. SIRT1 is significantly elevated in mouse and human prostate cancer. Cancer Res. 2007; 67(14):6612-6618. [PubMed: 17638871]

20. Stunkel W, Peh BK, Tan YC, et al. Function of the SIRT1 protein deacetylase in cancer. Biotechnol J. 2007; 2(11):1360-1368. [PubMed: 17806102]

21. Hida Y, Kubo Y, Murao K, Arase S. Strong expression of a longevity-related protein, SIRT1, in Bowen's disease. Arch Dermatol Res. 2007; 299(2):103-106. [PubMed: 17180656]

22. Lim CS. SIRT1: tumor promoter or tumor suppressor? MedHypotheses. 2006; 67(3):341-344. 
23. Ford J, Jiang M, Milner J. Cancer-specific functions of SIRT1 enablehuman epithelial cancer cell growth and survival. Cancer Res. 2005; 65(22):10457-10463. [PubMed: 16288037]

24. Heltweg B, Gatbonton T, Schuler AD, et al. Antitumor activity of asmall-molecule inhibitor of human silent information regulator 2enzymes. Cancer Res. 2006; 66(8):4368-4377. [PubMed: 16618762]

25. Ota H, Tokunaga E, Chang K, et al. Sirt1 inhibitor, Sirtinol, induces senescence-like growth arrest with attenuated Ras-MAPK signaling in human cancer cells. Oncogene. 2006; 25(2):176-185. [PubMed: 16170353]

26. Zhao W, Kruse JP, Tang Y, Jung SY, Qin J, Gu W. Negative regulation of the deacetylase SIRT1 by DBC1. Nature. 2008; 451(7178):587-590. [PubMed: 18235502]

27. Kim JE, Chen J, Lou Z. DBC1 is a negative regulator of SIRT1. Nature. 2008; 451(7178):583586. [PubMed: 18235501]

28. Lain S, Hollick JJ, Campbell J, et al. Discovery, in vivo activity, and mechanism of action of a small-molecule p53 activator. Cancer Cell. 2008; 13(5):454-463. [PubMed: 18455128]

29. Firestein R, Blander G, Michan S, et al. The SIRT1 deacetylase suppresses intestinal tumorigenesis and colon cancer growth. PLoS ONE. 2008; 3(4):e2020. [PubMed: 18414679]

30. Mullan PB, Quinn JE, Harkin DP. The role of BRCA1 in transcriptional regulation and cell cycle control. Oncogene. 2006; 25(43):5854-5863. [PubMed: 16998500]

31. Altieri DC. Survivin, cancer networks and pathway-directed drug discovery. Nat Rev Cancer. 2008; 8(1):61-70. [PubMed: 18075512]

32. Wang RH, Zheng Y, Kim HS, et al. Interplay among BRCA1, SIRT1, and Survivin during BRCA1-associated tumorigenesis. Mol. Cell. 2008; 32(1):11-20. [PubMed: 18851829]

33. Yeung F, Hoberg JE, Ramsey CS, et al. Modulation of NF-kappaB-dependent transcription and cell survival by the SIRT1 deacetylase. EMBO J. 2004; 23(12):2369-2380. [PubMed: 15152190]

34. Wang RH, Sengupta K, Li C, et al. Impaired DNA damage response, genome instability, and tumorigenesis in SIRT1 mutant mice. Cancer Cell. 2008; 14(4):312-323. [PubMed: 18835033]

35. Jeong J, Juhn K, Lee H, et al. SIRT1 promotes DNA repair activity and deacetylation of Ku70. Exp Mol Med. 2007; 39(2):8-13. [PubMed: 17334224]

36. Li K, Casta A, Wang R, et al. Regulation of WRN protein cellular localization and enzymatic activities by SIRT1-mediated deacetylation. J Biol Chem. 2008; 283(12):7590-7598. [PubMed: 18203716]

37. Yuan Z, Zhang X, Sengupta N, Lane WS, Seto E. SIRT1 regulates the function of the Nijmegen breakage syndrome protein. Mol Cell. 2007; 27(1):149-162. [PubMed: 17612497]

38. Oberdoerffer P, Michan S, McVay M, et al. SIRT1 redistribution on chromatin promotes genomic stability but alters gene expression during aging. Cell. 2008; 135(5):907-918. [PubMed: 19041753]

39. Fan W, Luo J. SIRT1 regulates UV-induced DNA repair through deacetylating XPA. Mol. Cell. 2010; 39(2):247-258. [PubMed: 20670893]

40. McBurney MW, Yang X, Jardine K, et al. The mammalian SIR2alpha protein has a role in embryogenesis and gametogenesis. Mol. Cell. Biol. 2003; 23(1):38-54. [PubMed: 12482959]

41. Cheng H, Mostoslavsky R, Saito S, et al. Developmental defects and p53 hyperacetylation in Sir2 homolog (SIRT1)-deficient mice. Proc. Natl. Acad. Sci. U.S.A. 2003; 100(19):10794-10799. [PubMed: 12960381]

42. Schug TT, Xu Q, Gao H, et al. Myeloid deletion of SIRT1 induces inflammatory signaling in response to environmental stress. Mol Cell Biol. 2010; 30(19):4712-4721. [PubMed: 20647536]

43. Cohen DE, Supinski AM, Bonkowski MS, Donmez G, Guarente LP. Neuronal SIRT1 regulates endocrine and behavioral responses to calorie restriction. Genes Dev. 2009; 23(24):2812-2817. [PubMed: 20008932]

44. Ramadori G, Fujikawa T, Fukuda M, et al. SIRT1 deacetylase in POMC neurons is required for homeostatic defenses against diet-induced obesity. Cell Metab. 12(1):78-87. [PubMed: 20620997]

45. Purushotham A, Schug TT, Xu Q, Surapureddi S, Guo X, Li X. Hepatocyte-specific deletion of SIRT1 alters fatty acid metabolism and results in hepatic steatosis and inflammation. Cell Metab. 2009; 9(4):327-338. [PubMed: 19356714] 
46. Chen D, Bruno J, Easlon E, et al. Tissue-specific regulation of SIRT1 by calorie restriction. Genes Dev. 2008; 22(13):1753-1757. [PubMed: 18550784]

47. Herranz D, Munoz-Martin M, Canamero M, et al. Sirt1 improves healthy ageing and protects from metabolic syndrome-associated cancer. Nat Commun. 2010; 1:3. [PubMed: 20975665] 